\title{
Muscle sympathetic nerve activity during exercise
}

\author{
Keisho Katayama ${ }^{1,2} \cdot$ Mitsuru Saito $^{3}$
}

Received: 3 January 2019 / Accepted: 22 February 2019 / Published online: 3 May 2019

(c) The Physiological Society of Japan and Springer Japan KK, part of Springer Nature 2019

\begin{abstract}
Appropriate cardiovascular adjustment is necessary to meet the metabolic demands of working skeletal muscle during exercise. The sympathetic nervous system plays a crucial role in the regulation of arterial blood pressure and blood flow during exercise, and several important neural mechanisms are responsible for changes in sympathetic vasomotor outflow. Changes in sympathetic vasomotor outflow (i.e., muscle sympathetic nerve activity: MSNA) in inactive muscles during exercise differ depending on the exercise mode (static or dynamic), intensity, duration, and various environmental conditions (e.g., hot and cold environments or hypoxic). In 1991, Seals and Victor [6] reviewed MSNA responses to static and dynamic exercise with small muscle mass. This review provides an updated comprehensive overview on the MSNA response to exercise including large-muscle, dynamic leg exercise, e.g., two-legged cycling, and its regulatory mechanisms in healthy humans.
\end{abstract}

Keywords MSNA · Leg cycling · Sympathetic nerve activity · Blood pressure

\section{Introduction}

Precise cardiovascular and hemodynamic adjustments are necessary to meet the metabolic demand of active skeletal muscle. An appropriate regulation of sympathetic vasomotor outflow is key for maintaining arterial blood pressure and to facilitate the delivery of blood flow to active skeletal muscle. Central command (a feedforward mechanism originating from the cerebral cortex and/or subcortical nuclei), the exercise pressor reflex (a feedback mechanism originating from skeletal muscle, i.e., metaboreflex and mechanoreflex), the arterial baroreflex (a negative feedback mechanism originating from the carotid sinus and aortic arch), and cardiopulmonary baroreflex (a negative feedback mechanism originating from low-pressure mechanically sensitive stretch receptors located in the heart, vena cava and blood vessels of the lungs) work in concert creating complex interactions that regulate sympathetic vasomotor outflow during exercise

Keisho Katayama

katayama@htc.nagoya-u.ac.jp

1 Research Center of Health, Physical Fitness and Sports, Nagoya University, Nagoya 464-8601, Japan

2 Graduate School of Medicine, Nagoya University, Nagoya, Japan

3 Applied Physiology Laboratory, Toyota Technological Institute, Nagoya, Japan
[1-4]. Alternations in sympathetic nerve activity during exercise have been inferred from changes in plasma norepinephrine concentrations. The main interpretive limitation of this measurement is that plasma levels are influenced by norepinephrine release and reuptake of norepinephrine [5, 6]. In addition, changes in plasma norepinephrine are progressing slowly, resulting in low time resolution. Therefore, direct measurement of sympathetic nervous activity is needed to provide more definitive insight into the effect of exercise. In 1972, Delius et al. [7] reported, for the first time, an increase in muscle sympathetic nerve activity (MSNA) during sustained muscle contractions (handgrip and leg adduction). Thereafter, numerous investigators have reported the MSNA response to exercise. These studies have revealed that the change in MSNA differs considerably depending on the exercise mode (static or dynamic), exercise intensity, duration of exercise, and environment (normoxia or hypoxia). In 1991, Seals and Victor [6] reviewed articles concerning MSNA responses to exercise in humans. At that time, no data on the MSNA responses to dynamic leg exercise with large muscle mass were available. This review aimed to provide an updated comprehensive overview on the MSNA response to exercise including large-muscle, dynamic leg exercise, e.g., two-legged cycling, and its regulatory mechanisms in healthy humans. 


\section{Microneurography}

Microneurography is a technique that can be used to measure and record the electrical activity of the postganglionic sympathetic nerve [8-10]. In humans, MSNA can be measured from the radial, median, and ulnar nerves in the upper limb and from the peroneal and tibial nerves in the lower limb $[10,11]$. Although microneurography has several limitations $[9,12]$, it is a gold standard for the assessment of sympathetic vasomotor outflow. The limb of the MSNA recording site must remain relaxed to avoid electromyographic contamination; thus, measurements of MSNA to contracting muscle are not possible, and MSNA has been recorded from inactive limb. The most recorded peripheral nerve is the peroneal nerve at the fibular head, and the subjects perform handgrip [13-21], arm cycling [13, 18, 22-24] or one-legged dynamic exercise [25-27]. Additionally, several researchers have measured MSNA from the radial [28, 29] or median nerve [30-35] during two-legged cycling. Real-time ultrasound guidance with microneurography has recently been utilized [11]. The assessment of MSNA is often an integrated signal of multiple nerve fibers presented as burst frequency (bursts/min), burst incidence (bursts/100 heart beats), and total activity (mean burst amplitude or burst area $\times$ number of bursts) [9]. In addition to the difficulty of recording MSNA during dynamic two-legged cycling, in some cases it is difficult to analyze burst amplitude and, thereby, total activity because electromyographic, efferent, and afferent nerve activities alter the baseline of the integrated neurogram during dynamic leg cycling [30, 31, 35]. For a more in-depth discussion of MSNA measurement methods and analyses, we refer the reader to previous, more detailed reviews $[9,36]$.

\section{Regulation of MSNA}

In this review, we focus on representative studies on MSNA regulation during exercise in humans. The reader is referred to a number of excellent reviews [1-4] that provide a much higher level of detail on individual topics.

\section{Central command}

The concept that signals from the higher brain contribute to the cardiovascular and hemodynamic adjustments to exercise has been well presented for over a century [1, 3, 4]. Originally termed "cortical irradiation", and now known as "central command", this refers to descending neural signals that involve the parallel activation of the somatomotor, respiratory, and cardiovascular systems [37]. The traditional supposition has been that central command sets the initial pattern of autonomic activation to the heart and blood vessels at the onset of exercise [37-39]. To determine the influence of central command on sympathetic vasomotor outflow, Mark et al. [14] compared MSNA responses during voluntary and involuntary (percutaneous electrical stimulation) biceps contraction at $20 \%$ maximal voluntary contraction (MVC). MSNA increased during involuntary contraction but decreased during voluntary contraction. This result suggests that during static exercise with small muscle mass, central command does not increase but, rather, inhibits MSNA. Victor et al. [40, 41] investigated whether central command affects MSNA during static and intense intermittent isometric handgrip exercise with and without partial neuromuscular blockade. During static handgrip exercise at $15 \%$ and $30 \% \mathrm{MVC}$ and intermittent isometric handgrip exercise at $25 \%$ and $50 \% \mathrm{MVC}$, central command had very little effect on MSNA. In contrast, intermittent isometric handgrip exercise at $75 \%$ MVC induced an increase in MSNA [41]. These results suggest that central command increases MSNA only during higher intensities of exercise $[1,3,4]$. To date, no data on the influence of central command on MSNA responses to dynamic exercise with large muscle mass are available.

\section{Exercise pressor reflex}

A lot of researchers have devoted themselves to understanding the feedback mechanisms emanating from active skeletal muscle, and the importance of the exercise pressor reflex to the arterial blood pressure during dynamic exercise has been demonstrated [1, 3, 4, 42]. Skeletal muscle afferents are comprised of mechanically and metabolically sensitive sensory fibers (myelinated group III and unmyelinated group IV afferent fibers) that provide feedback to cardiovascular control areas in the brain stem [43-45]. Importantly, these temporal profiles for the activation of chemically sensitive receptors and channels are not absolute, since both group III and IV afferent fibers exhibit polymodal qualities $[3,43]$. It has been suggested that the activation of both mechanically and metabolically sensitive afferent fibers contributes to exercise pressor reflex-mediated sympathetic vasomotor outflow $[1,3,4]$. It is very challenging to isolate the stimulation of mechanoreceptors in humans; primary adopted strategies include passive muscle stretch or passive limb movement. Indeed, Middlekauff et al. [46] recorded MSNA during passive arm extension/flexion movement, and MSNA remained unchanged from baseline during passive movement in healthy subjects. Cui et al. [47] investigated whether isolated stimulation of the mechanoreceptors can induce responses in MSNA. They found that passive leg calf muscle stretching induced transient increases in MSNA, supporting the idea that mechanoreceptors in muscles play a role in evoking the sympathetic response. During fatiguing 
isometric muscle contraction, the activity of muscle mechanoreceptors typically increases [48]. Thus, the accumulation of metabolites within active skeletal muscle can sensitize mechanically sensitive skeletal muscle afferents [4]. In contrast to the mechanoreflex, numerous human studies have shown a rather robust ability of the muscle metaboreflex to induce increases in MSNA. The majority of studies have used post-exercise ischemia to trap exercise-induced metabolites within the previously active muscle $[4,14,49]$, e.g., an occlusion cuff placed over the upper arm is inflated to suprasystolic pressure ( $>240 \mathrm{mmHg}$ ) after handgrip exercise. Thus, their stimulatory effect on metabolically sensitive skeletal muscle afferents is preserved in the absence of the muscle mechanoreflex and central command [1]. This maneuver has been consistently shown to maintain a major portion $(\sim 85 \%)$ of the exercise-induced increase in MSNA $[1,14]$ in an exercise intensity-dependent manner [50].

\section{Arterial baroreflex}

Arterial baroreceptors are located in the carotid artery and aorta and play a key role in the rapid sympathetic vasomotor adjustments to acute cardiovascular stressors [2]. These baroreceptors are mechanically sensitive and function as sensors in a negative feedback control loop that responds to beat-to-beat changes in arterial blood pressure [1, 3, 4]. When arterial blood pressure is elevated, baroreceptors are stretched, leading to further increases in afferent firing and resulting in a reflex-mediated decrease in MSNA [2]. In contrast, when arterial blood pressure decreases, tonic afferent firing is decreased, resulting in an increase in MSNA [2]. These neural adjustments affect blood vessels (altering total vascular conductance), to return arterial blood pressure to its original set point pressure [2,3]. The ability of the arterial baroreflex to regulate arterial blood pressure is critically dependent on alterations in vascular tone both at rest and during exercise. Indeed, some studies have reported a progressive resetting of the baroreflex control of MSNA, to operate around the exercise-induced elevations in arterial blood pressure with maintained or increased sensitivity $[23,24,51,52]$. Therefore, the arterial baroreflex control of MSNA is well maintained throughout a bout of exercise, and the arterial baroreflex plays an important role in the regulation of MSNA during exercise [1-4].

\section{Cardiopulmonary baroreflex}

Cardiopulmonary baroreceptors are mechanically sensitive stretch receptors located in the heart, vena cava, and blood vessels of the lungs that sense changes in central blood volume and pressure [53-55] and reflexively modulate MSNA. These phenomena have been revealed by multiple studies that recorded MSNA during lower body negative pressure and lower body positive pressure at resting conditions [15-17, 50, 56-58]. The cardiopulmonary baroreflex during dynamic exercise has been but seldom studied, and most representative work was performed by Ray et al. [25] who showed that MSNA was affected by changes in central blood volume mediated by the cardiopulmonary baroreflex during dynamic one-legged knee extension exercise in the sitting and supine positions. They found a reduction in MSNA below resting levels when exercise was performed in the sitting position, while no changes in MSNA were observed when exercise was performed in the supine position. Based on these data, it is believed that a decrease in MSNA in dynamic leg exercise is linked to the loading of cardiopulmonary baroreceptors, which is attributable to muscle pump-induced increases in venous return or central blood volume $[2,25,55,59,60]$. We [61] recently demonstrated that the enhanced muscle pump-induced increase in central blood volume led to decreased MSNA during two-legged cycling. Ogoh et al. [62] revealed that increasing the central blood volume, which loads the cardiopulmonary baroreceptors, reduces the magnitude of the exercise-induced increase in arterial blood pressure with the arterial baroreflex resetting. Importantly, the effect of the cardiopulmonary baroreflex on MSNA would be overcome by the skeletal muscle metaboreflex during high-intensity exercise [2, 50]. Overall, the cardiopulmonary baroreflex contributes to the regulation of MSNA during dynamic exercise at light or mild intensity.

\section{Respiratory modulation}

The respiratory modulation of MSNA is very clear in humans [63], and MSNA declines during inspiration, reaching its nadir at peak inspiration (when the lung volume is the highest and central respiratory motor output is at its peak) and then rises, reaching its peak at end expiration (when respiratory motor output and lung volume are the lowest) [64-67]. Potential mediators of the fluctuations in MSNA during respiration include coincident small changes in systemic blood pressure and lung volume. It seems, most likely, that the greatest influence of afferent input from pulmonary stretch receptors is in modulating sympathetic responsiveness to baroreceptor influences, although the respiratory modulation of MSNA remains complex and incompletely understood [63]. In addition, it has been assumed that carotid chemoreceptors are related to exerciseinduced increases in MSNA [68]. To test this assumption, Stickland et al. [69] applied hyperoxic gas (inspired oxygen fraction $\left[\mathrm{FIO}_{2}\right]=1.00$ ) to inhibit carotid chemoreceptor activity at rest and during rhythmic handgrip exercise with MSNA measurement. Transient hyperoxia had no significant effect on MSNA at rest, while MSNA decreased with hyperoxia during exercise. These results support the assumption that carotid chemoreceptors contribute to sympathetic 
vasoconstrictor outflow during exercise in humans. It is well known that high-intensity whole-body exercise leads to respiratory muscle fatigue [70, 71]. Fatiguing respiratory muscle work and the accumulation of metabolites are associated with neural and cardiovascular consequences, resulting in a redistribution of blood flow during exercise [68, 72]. Indeed, Dempsey and colleagues [35, 73-75] have reported that imposing a high work of breathing modulates MSNA at rest and during mild leg cycling with corresponding increases in arterial blood pressure and leg vascular resistance. This sympathoexcitation occurs through an inspiratory muscleinduced metaboreflex [76-78]. Dominelli et al. [79] recently confirmed a decrease in MSNA during two-legged cycling at moderate and high intensity when the work of breathing was reduced by a proportional assist ventilator. Based on these results, the respiratory muscle-induced metaboreflex contributes to the regulation of MSNA during dynamic leg exercise above moderate intensity.

\section{MSNA responses to exercise}

\section{Static exercise}

\section{Upper limb exercise}

Numerous studies have confirmed increased MSNA during sustained handgrip exercise [14, 19, 21, 40, 50, 80-83]. The change in MSNA during sustained handgrip exercise increases in proportion to exercise intensity $[6,15,17,21$, 40, 80] (Fig. 1a). The main mechanism of the increased MSNA during sustained exercise is associated with the accumulation of metabolites in active muscle, i.e., the muscle metaboreflex.

\section{Lower limb exercise}

Some researchers have reported increased MSNA during sustained foot plantar flexion or dorsiflexion [81, 84] and isometric knee extension [85, 86]. Interestingly, when the static exercise performed in lower limb (knee extension) and exercise intensity is below $30 \%$ of maximal voluntary contraction (MVC), a temporal decrease in MSNA appears relative to that at rest (Fig. 1b). Then a time-dependent increase in MSNA appeared during static leg exercise [85].

Generally, MSNA does not increase during sustained exercise in the upper or lower limb if the exercise intensity is below $15 \% \mathrm{MVC}$ and if the exercise duration lasts several minutes [17, 21, 40]. At the same relative exercise intensity and same duration, the magnitude (percentage) of the increased MSNA from baseline appears larger during upper limb than lower limb exercise. There are some cases in which MSNA decreased slightly over the first minutes during static light leg exercise when exercise was performed in a sitting, but not supine, position $[85,86]$. Therefore, stimulating cardiopulmonary baroreceptors by increasing venous return may be related to decreased MSNA during static light leg exercise, although the mechanisms are unclear.

\section{Dynamic exercise}

\section{Upper limb exercise}

MSNA does not increase during dynamic (rhythmic) exercise with small muscle mass (handgrip) for a brief duration ( $2 \mathrm{~min}$ ) when the exercise intensity is less than 50\% MVC (Fig. 2) [13, 18, 41, 69, 87-89]. When rhythmic handgrip exercise at $25 \% \mathrm{MVC}$ is prolonged $(\sim 30 \mathrm{~min})$, a progressive increase in MSNA appears [90] (Fig. 2). Regarding arm cycling, MSNA does not increase up to $30 \%$ maximal
Fig. 1 Changes in MSNA during static exercise in the upper (a) and lower limb (b) (isometric handgrip exercise and isometric foot planter flexion or dorsiflexion and isometric knee extension, respectively). Percent changes in MSNA from baseline were calculated by MSNA data (bursts/min) in published articles. a [14, 17, 19, $21,40,50,80,81,83,86], \mathbf{b}$ $[81,84,86]$
Static exercise in upper limb (handgrip)

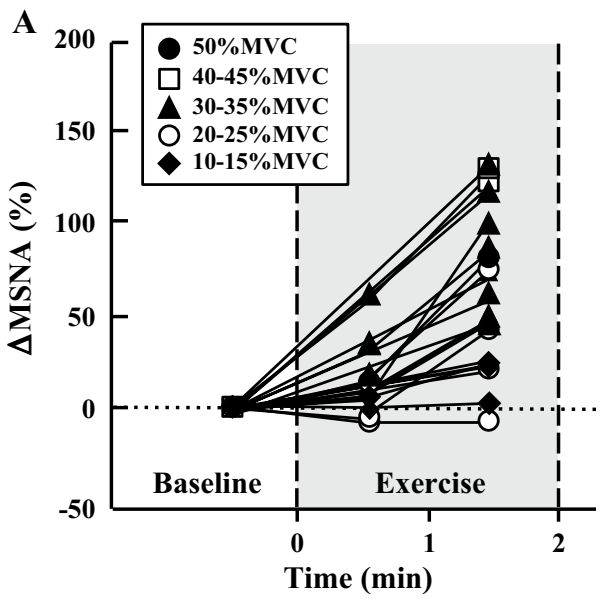

Static exercise in lower limb (foot plantar flection or dorsiflexion and knee extension)

B

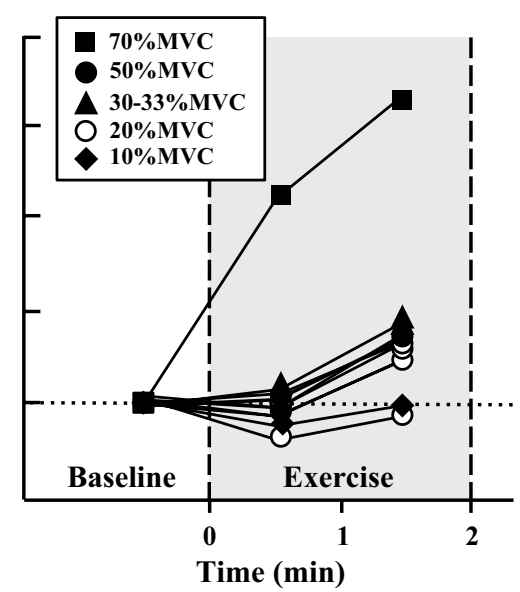




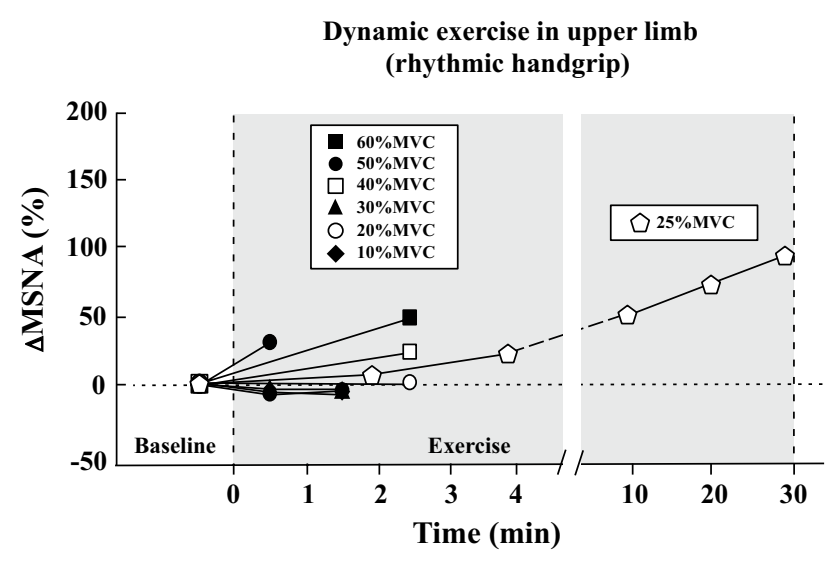

Fig. 2 Changes in MSNA during dynamic exercise in the upper limb (rhythmic handgrip exercise). Percent changes in MSNA from baseline were calculated by MSNA data (bursts/min or total activity/min) in published articles $[13,18,69,89,90]$

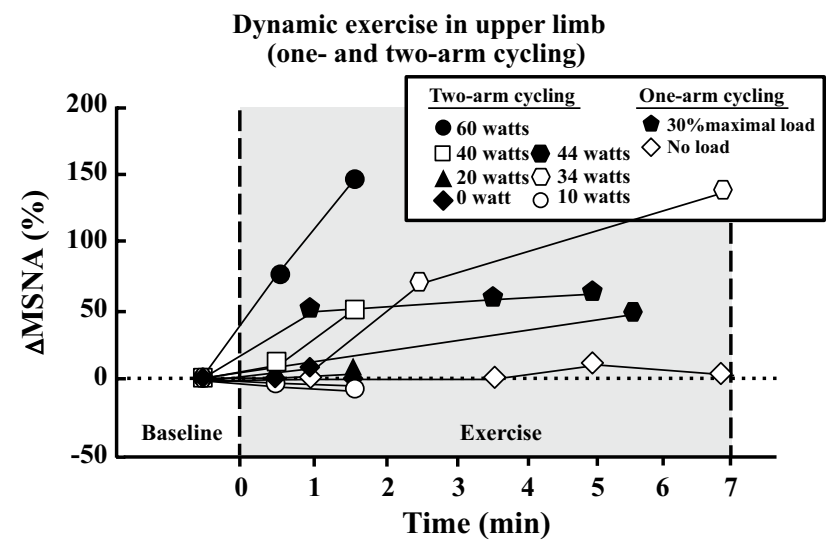

Fig. 3 Changes in MSNA during dynamic exercise in the upper limb (one- and two-arm cycling). Percent changes in MSNA from baseline were calculated by MSNA data (bursts/min) in published articles [13, $18,23,24]$

workload or $\sim 30$ watts over the first several minutes $[13,18]$, while MSNA does increase above 40 watts and $50 \%$ peak oxygen uptake $\left(\mathrm{VO}_{2 \text { peak }}\right)[13,23,24]$ (Fig. 3).

\section{Lower limb exercise}

Several research groups have attempted to record MSNA during dynamic leg exercise (Fig. 4). In 1993, Saito et al. [30] recorded MSNA from the median nerve during twolegged cycling at different intensities; MSNA decreased at a light intensity $\left(20 \% \mathrm{VO}_{2 \text { peak }}\right)$ relative to that at rest and returned to the resting level at mild intensity $\left(40 \% \mathrm{VO}_{2 \text { peak }}\right)$. These results were consistent with those obtained during one-legged cycling in their previous study [91]. This result indicates an inhibition of sympathetic vasomotor outflow during leg cycling at light and mild intensities. Above moderate intensity, MSNA during two-legged exercise gradually rose in proportion to the increase in workload [30]. This interesting phenomenon confirmed later studies that utilized one-legged [27, 28] and two-legged cycling [29, 35, 61, 74, $75,92,93]$. The mechanism of the inhibition of MSNA during dynamic leg exercise at light and mild intensity is due to loading of the cardiopulmonary baroreceptors, which is induced by a muscle pump-induced increase in venous return and central blood volume [2, 25, 55, 59, 60]. The above-mentioned studies recorded MSNA less than 7 min at each intensity, and the changes in MSNA were strongly influenced by exercise duration. Ray et al. [26] reported changes in MSNA during prolonged dynamic exercise. The subjects performed dynamic one-legged knee extension exercise at 30 watts in an upright posture for $40 \mathrm{~min}$. MSNA decreased during exercise during the first $10 \mathrm{~min}$ and returned to resting levels by $20 \mathrm{~min}$ and remained by $40 \mathrm{~min}$ (heart rate $[\mathrm{HR}]=110$ beats $/ \mathrm{min}$ at $40 \mathrm{~min}$ ) (Fig. 5). Moreover, Saito et al. [31] revealed changes in MSNA during two-legged cycling at $40 \% \mathrm{VO}_{2 \text { peak }}$ for $30 \mathrm{~min}$ in a semirecumbent position; MSNA decreased during the first 10 min of cycling and then gradually increased above baseline by $30 \mathrm{~min}(\mathrm{HR}=113$ beats $/ \mathrm{min}$ at $30 \mathrm{~min})$ (Fig. 5). The gradual increase in MSNA during prolonged leg cycling at mild intensity could be related to cardiovascular drift. Cardiovascular drift is defined as a continuous time-dependent change in some cardiovascular variables after $\sim 10 \mathrm{~min}$ of prolonged moderate-intensity exercise [94-96]. General responses include reductions in stroke volume and arterial blood pressure and a parallel increase in HR, which are due to progressive increases in cutaneous blood flow and cutaneous vasodilation, as the body temperature rises. Thus, it is likely that a reduction of arterial blood pressure elicits an increase in MSNA during prolonged two-legged cycling [94]. In addition, central command and/or exercise pressor reflex may also contribute to a gradual increase in MSNA during prolonged exercise.

\section{Environment}

Heat stress induces increases in MSNA with raises in body temperature. Niimi et al. [97] measured resting MSNA with ambient temperatures of 29,34 , and $40{ }^{\circ} \mathrm{C}$ in an artificial climate chamber. They found progressive increases in MSNA during heat stress with rises in tympanic temperature. The increases in MSNA in response to acute heat stress could cause the redistribution of the circulatory blood flow from the muscles to the skin. Recently, Cui et al. [98] examined whether neural and cardiovascular response to stimulation of muscle metaboreceptors and mechanoreceptors are modified if body temperature is elevated before exercise. The magnitude increase in MSNA during handgrip exercise and 
Fig. 4 Changes in MSNA during dynamic exercise in the lower limb (two-legged or onelegged cycling). Exercise duration is within $6 \mathrm{~min}$. Percent changes in MSNA from baseline were calculated by MSNA data (bursts/min) in published articles. a [27, 30, 31, 35, 61, $74,75,79,93], \mathbf{b}[51,91]$
Dynamic exercise in lower limb

(one- and two-leg cycling)

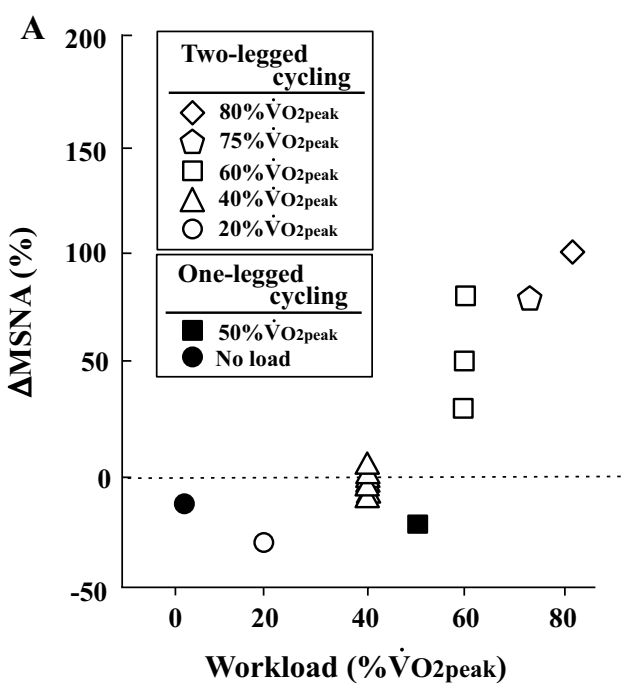

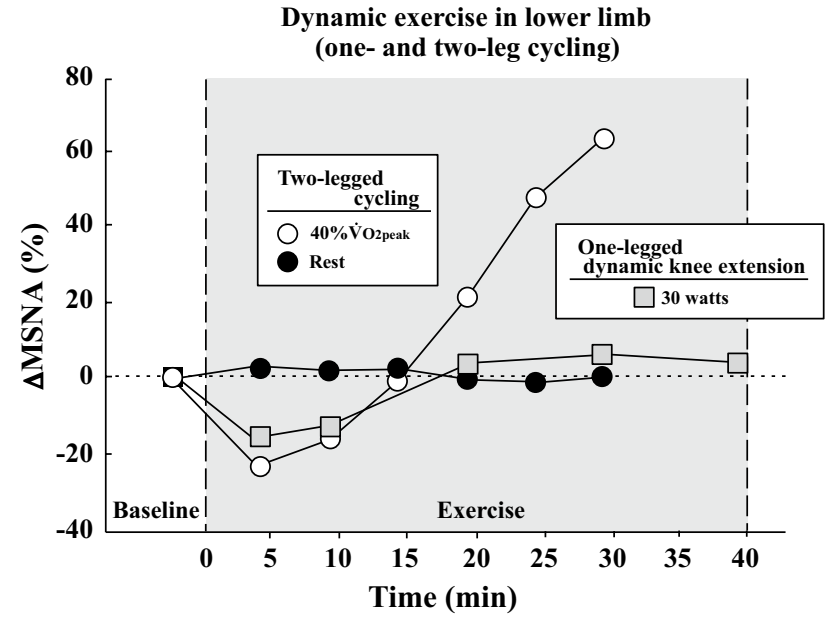

Fig. 5 Changes in MSNA during dynamic prolonged exercise in the lower limb (two-legged cycling and one-legged dynamic knee extension). Percent changes in MSNA from baseline were calculated by MSNA data (bursts/min) in published articles [26, 31]

post-exercise ischemia did not alter under whole body heat stress. However, MSNA response to exercise depends on the duration and intensity of the activity. Even if under normothermic conditions $\left(21-25{ }^{\circ} \mathrm{C}\right)$, body temperature rises when dynamic leg cycling is prolonged, eliciting progressive increases in MSNA [31]. Thus, an increase in MSNA during whole-body exercise may potentiate in hot environment.

Sympathetic vasomotor outflow regulating arterial blood pressure changes with exposure to a cold environment. A representative maneuver is the cold pressure test whereby one hand is immersed in cold water for several minutes [99], and immersion evokes an increase in MSNA [100]. Fagius et al. [101] examined the effect of whole-body exposure to a cold environment $\left(22.7-10.5^{\circ} \mathrm{C}\right)$ on MSNA at rest, and a significant increase in MSNA appeared at a low environmental temperature, with simultaneous increase in arterial blood pressure. The increase in MSNA may play a role in body temperature regulation by preserving heat within the central core [101]. To our knowledge, little is known about the possible modulatory effects of cold environment on MSNA during exercise in humans. Further investigations are needed to clarify the MSNA responses during whole-body exercise in hot and cold environments.

Hypoxia produces a significant increase in sympathetic tone, to redistribute the blood to supply oxygen to vital organs. It is well known that acute hypoxia at rest induces an increase in MSNA in humans [102-104], and the magnitude of the MSNA response to brief hypoxia depends on the level and duration of hypoxic exposure. In healthy humans, a significant increase in MSNA appears when arterial oxygen saturation $\left(\mathrm{SaO}_{2}\right)$ levels are below $80 \%$ [105] $\left(\mathrm{FIO}_{2}\right.$ is below 0.125 or the altitude is above $4000 \mathrm{~m}$ ), although there are wide individual differences. There are a lot of situations in which people perform exercise under hypoxic conditions, e.g., at high altitude or with pathophysiological conditions. Seals et al. [106] found a significant increase in MSNA during rhythmic handgrip exercise in hypoxia $\left(\mathrm{FIO}_{2}=0.10\right)$. The magnitude of the increase in MSNA during hypoxic exercise was greater than the sum of the separate MSNA responses to the same exercise in normoxia and at resting level in hypoxia, suggesting an interaction between hypoxia and exercise effects. However, when rhythmic exercise was performed with blood flow occlusion, the extent of the MSNA response in normoxia did not differ from that in hypoxia $[6,106]$. The latter results are consistent with 
those by Saito et al. [107] who showed that the magnitude of the MSNA response to static exercise was not altered under hypoxic conditions relative to normoxic conditions. These data indicate that the mechanism for the potentiation of the response to dynamic exercise with small muscle mass under hypoxic conditions originates in the contracting muscle [6, 106]. It would be interesting to evaluate the MSNA during dynamic leg exercise under hypoxic conditions. We [33] attempted to record MSNA during mild and moderate twolegged cycling under normoxic $\left(\mathrm{FIO}_{2}=0.209\right)$ and hypoxic conditions $\left(\mathrm{FIO}_{2}=0.127\right)$. Consequently, MSNA increased at $40 \% \mathrm{VO}_{2 \text { peak }}$ exercise in hypoxia, but not in normoxia. These results suggest that acute hypoxia potentiates the MSNA response during dynamic exercise with large muscle mass and that hypoxia-induced heightened sympathetic nerve activity during dynamic leg exercise attenuates the cardiopulmonary baroreflex control of sympathetic vasomotor outflow.

\section{Relationship between MSNA and plasma norepinephrine concentrations}

Changes in sympathetic nerve activity during exercise have been estimated from alterations in plasma norepinephrine concentrations [108-111]. A significant relationship between plasma norepinephrine concentration and MSNA during arm cycling and static handgrip exercise were reported under normoxic conditions [22,112], although the relative (\%) increase in above baseline levels was larger in MSNA than in plasma norepinephrine concentrations. However, the changes in plasma norepinephrine concentrations during dynamic leg cycling at light and mild exercise differed from that in MSNA [33], suggesting that plasma norepinephrine concentrations during hypoxic exercise could be an imprecise and even misleading index of sympathetic nerve activity [103, 113, 114]. This reason may be attributed to increased norepinephrine concentration reuptake [115] and the inhibited neuronal release of norepinephrine during acute hypoxemia [103].

\section{Conclusions}

In this review, we provide an updated comprehensive overview on the MSNA response to exercise. Several groups have revealed changes in MSNA during large-muscle, dynamic leg exercise, e.g., two-legged cycling. MSNA decreases or is unchanged during two-legged cycling at light or mild intensity, suggesting the inhibition of sympathetic vasomotor outflow. This phenomenon is due to a muscle pump-induced increase in venous return and central blood volume, which loads cardiopulmonary baroreceptors. It is clear that the cardiopulmonary baroreflex plays a significant role in the regulation of sympathetic vasomotor outflow during dynamic exercise at light or mild intensity. During higher intensity dynamic exercise, it is plausible that the exercise pressor reflex from the active limb muscle in conjunction with the respiratory muscle-induced metaboreflex dominates to regulate sympathetic vasomotor outflow. Additionally, during high-intensity two-leg cycling, the respiratory muscle metaboreflex contributes to regulate sympathetic vasomotor outflow. Future studies are necessary to clarify 1) the interactions between central command, the exercise pressor reflex, the arterial baroreflex, the cardiopulmonary baroreflex, and the respiratory muscle metaboreflex, and 2) the MSNA responses during whole-body exercise in hot and cold environments or hypoxia.

Acknowledgements This paper was supported, in part, by JSPS KAKENHI Grant No., JP16KK0201.

\section{Compliance with ethical standards}

Conflict of interest The authors declare no competing interest.

\section{References}

1. Fadel PJ (2015) Reflex control of the circulation during exercise. Scand J Med Sci Sports 25(Suppl 4):74-82

2. Fadel PJ, Raven PB (2012) Human investigations into the arterial and cardiopulmonary baroreflexes during exercise. Exp Physiol 97:39-50

3. Mueller PJ, Clifford PS, Crandall CG, Smith SA, Fadel PJ (2017) Integration of central and peripheral regulation of the circulation during exercise: acute and chronic adaptations. Compr Physiol 8:103-151

4. Fisher JP, Young CN, Fadel PJ (2015) Autonomic adjustments to exercise in humans. Compr Physiol 5:475-512

5. Esler M, Jennings G, Korner P, Willett I, Dudley F, Hasking G, Anderson W, Lambert G (1988) Assessment of human sympathetic nervous system activity from measurements of norepinephrine turnover. Hypertension 11:3-20

6. Seals DR, Victor RG (1991) Regulation of muscle sympathetic nerve activity during exercise in humans. Exerc Sport Sci Rev 19:313-349

7. Delius W, Hagbarth KE, Hongell A, Wallin BG (1972) Manoeuvres affecting sympathetic outflow in human muscle nerves. Acta Physiol Scand 84:82-94

8. Joyner MJ, Wallin BG, Charkoudian N (2016) Sex differences and blood pressure regulation in humans. Exp Physiol 101:349-355

9. White DW, Shoemaker JK, Raven PB (2015) Methods and considerations for the analysis and standardization of assessing muscle sympathetic nerve activity in humans. Auton Neurosci 193:12-21

10. Vallbo AB, Hagbarth KE, Wallin BG (2004) Microneurography: how the technique developed and its role in the investigation of the sympathetic nervous system. J Appl Physiol 96:1262-1269

11. Curry TB, Charkoudian N (2011) The use of real-time ultrasound in microneurography. Auton Neurosci 162:89-93

12. Carter JR, Ray CA (2015) Sympathetic neural adaptations to exercise training in humans. Auton Neurosci 188:36-43 
13. Victor RG, Seals DR, Mark AL (1987) Differential control of heart rate and sympathetic nerve activity during dynamic exercise. Insight from intraneural recordings in humans. J Clin Invest 79:508-516

14. Mark AL, Victor RG, Nerhed C, Wallin BG (1985) Microneurographic studies of the mechanisms of sympathetic nerve responses to static exercise in humans. Circ Res 57:461-469

15. Scherrer U, Vissing SF, Victor RG (1988) Effects of lowerbody negative pressure on sympathetic nerve responses to static exercise in humans. Microneurographic evidence against cardiac baroreflex modulation of the exercise pressor reflex. Circulation 78:49-59

16. Sanders JS, Ferguson DW (1988) Cardiopulmonary baroreflexes fail to modulate sympathetic responses during isometric exercise in humans: direct evidence from microneurographic studies. J Am Coll Cardiol 12:1241-1251

17. Seals DR (1988) Cardiopulmonary baroreflexes do not modulate exercise-induced sympathoexcitation. J Appl Physiol 64:2197-2203

18. Victor RG, Seals DR (1989) Reflex stimulation of sympathetic outflow during rhythmic exercise in humans. Am J Physiol 257:H2017-H2024

19. Seals DR, Enoka RM (1989) Sympathetic activation is associated with increases in EMG during fatiguing exercise. J Appl Physiol 66:88-95

20. Seals DR (1989) Sympathetic neural discharge and vascular resistance during exercise in humans. J Appl Physiol 66:2472-2478

21. Seals DR, Chase PB, Taylor JA (1988) Autonomic mediation of the pressor responses to isometric exercise in humans. J Appl Physiol 64:2190-2196

22. Seals DR, Victor RG, Mark AL (1988) Plasma norepinephrine and muscle sympathetic discharge during rhythmic exercise in humans. J Appl Physiol 65:940-944

23. Fadel PJ, Ogoh S, Watenpaugh DE, Wasmund W, OlivenciaYurvati A, Smith ML, Raven PB (2001) Carotid baroreflex regulation of sympathetic nerve activity during dynamic exercise in humans. Am J Physiol Heart Circ Physiol 280:H1383-H1390

24. Ogoh S, Fisher JP, Raven PB, Fadel PJ (2007) Arterial baroreflex control of muscle sympathetic nerve activity in the transition from rest to steady-state dynamic exercise in humans. Am J Physiol Heart Circ Physiol 293:H2202-H2209

25. Ray CA, Rea RF, Clary MP, Mark AL (1993) Muscle sympathetic nerve responses to dynamic one-legged exercise: effect of body posture. Am J Physiol 264:H1-H7

26. Ray CA (1993) Muscle sympathetic nerve responses to prolonged one-legged exercise. J Appl Physiol 74:1719-1722

27. Notarius CF, Millar PJ, Murai H, Morris BL, Marzolini S, Oh P, Floras JS (2015) Divergent muscle sympathetic responses to dynamic leg exercise in heart failure and age-matched healthy subjects. J Physiol 593:715-722

28. Callister R, Ng AV, Seals DR (1994) Arm muscle sympathetic nerve activity during preparation for and initiation of legcycling exercise in humans. J Appl Physiol 77:1403-1410

29. Moralez G, Jouett NP, Tian J, Zimmerman MC, Bhella P, Raven PB (2018) Effect of centrally acting angiotensin converting enzyme inhibitor on the exercise-induced increases in muscle sympathetic nerve activity. J Physiol 596:2315-2332

30. Saito M, Tsukanaka A, Yanagihara D, Mano T (1993) Muscle sympathetic nerve responses to graded leg cycling. J Appl Physiol 75:663-667

31. Saito M, Sone R, Ikeda M, Mano T (1997) Sympathetic outflow to the skeletal muscle in humans increases during prolonged light exercise. J Appl Physiol 82:1237-1243
32. Ichinose M, Saito M, Kitano A, Hayashi K, Kondo N, Nishiyasu $\mathrm{T}$ (2004) Modulation of arterial baroreflex dynamic response during mild orthostatic stress in humans. J Physiol 557:321-330

33. Katayama K, Ishida K, Iwamoto E, Iemitsu M, Koike T, Saito M (2011) Hypoxia augments muscle sympathetic neural response to leg cycling. Am J Physiol Regul Integr Comp Physiol 301:R456-R464

34. Katayama K, Ishida K, Saito M, Koike T, Ogoh S (2016) Hypoxia attenuates cardiopulmonary reflex control of sympathetic nerve activity during mild dynamic leg exercise. Exp Physiol 101:377-386

35. Katayama K, Iwamoto E, Ishida K, Koike T, Saito M (2012) Inspiratory muscle fatigue increases sympathetic vasomotor outflow and blood pressure during submaximal exercise. Am J Physiol Regul Integr Comp Physiol 302:R1167-R1175

36. Shoemaker JK, Klassen SA, Badrov MB, Fadel PJ (2018) Fifty years of microneurography: learning the language of the peripheral sympathetic nervous system in humans. J Neurophysiol 119:1731-1744

37. Goodwin GM, McCloskey DI, Mitchell JH (1972) Cardiovascular and respiratory responses to changes in central command during isometric exercise at constant muscle tension. J Physiol 226:173-190

38. Krogh A, Lindhard J (1913) The regulation of respiration and circulation during the initial stages of muscular work. J Physiol $47: 112-136$

39. Mitchell JH (1985) Cardiovascular control during exercise: central and reflex neural mechanisms. Am J Cardiol 55:34D-41D

40. Victor RG, Pryor SL, Secher NH, Mitchell JH (1989) Effects of partial neuromuscular blockade on sympathetic nerve responses to static exercise in humans. Circ Res 65:468-476

41. Victor RG, Secher NH, Lyson T, Mitchell JH (1995) Central command increases muscle sympathetic nerve activity during intense intermittent isometric exercise in humans. Circ Res 76:127-131

42. Strange S, Secher NH, Pawelczyk JA, Karpakka J, Christensen NJ, Mitchell JH, Saltin B (1993) Neural control of cardiovascular responses and of ventilation during dynamic exercise in man. $\mathbf{J}$ Physiol 470:693-704

43. Mitchell JH (1990) J.B. Wolffe memorial lecture. Neural control of the circulation during exercise. Med Sci Sports Exerc 22:141-154

44. Smith SA, Mitchell JH, Garry MG (2006) The mammalian exercise pressor reflex in health and disease. Exp Physiol 91:89-102

45. Kaufman MP, Foster HV (1996) Reflexes controlling circulatory, ventilatory, and airway responses to exercise. In: Rowell LB, Shepherd JT (eds) Exercise: regulation and integration of multiple systems. American Physiological Society, Bethsda

46. Middlekauff HR, Chiu J, Hamilton MA, Fonarow GC, Maclellan WR, Hage A, Moriguchi J, Patel J (2004) Muscle mechanoreceptor sensitivity in heart failure. Am J Physiol Heart Circ Physiol 287:H1937-H1943

47. Cui J, Blaha C, Moradkhan R, Gray KS, Sinoway LI (2006) Muscle sympathetic nerve activity responses to dynamic passive muscle stretch in humans. J Physiol 576:625-634

48. Kaufman MP, Longhurst JC, Rybicki KJ, Wallach JH, Mitchell JH (1983) Effects of static muscular contraction on impulse activity of groups III and IV afferents in cats. J Appl Physiol Respir Environ Exerc Physiol 55:105-112

49. Holwerda SW, Restaino RM, Manrique C, Lastra G, Fisher JP, Fadel PJ (2016) Augmented pressor and sympathetic responses to skeletal muscle metaboreflex activation in type 2 diabetes patients. Am J Physiol Heart Circ Physiol 310:H300-H309

50. Katayama K, Kaur J, Young BE, Barbosa TC, Ogoh S, Fadel PJ (2018) High-intensity muscle metaboreflex activation 
attenuates cardiopulmonary baroreflex-mediated inhibition of muscle sympathetic nerve activity. J Appl Physiol 125:812-819

51. Ichinose M, Saito M, Fujii N, Ogawa T, Hayashi K, Kondo N, Nishiyasu T (2008) Modulation of the control of muscle sympathetic nerve activity during incremental leg cycling. J Physiol 586:2753-2766

52. Keller DM, Fadel PJ, Ogoh S, Brothers RM, Hawkins M, Olivencia-Yurvati A, Raven PB (2004) Carotid baroreflex control of leg vasculature in exercising and non-exercising skeletal muscle in humans. J Physiol 561:283-293

53. Mark AL, Mancia G (1983) Cardiopulmonary baroreflexes in humans. In: Berne RM (ed) Handbook of physiology, the cardiovascular system, peripheral circulation and organ blood flow. American Physiological Society, Bethesda, pp 795-813

54. Hainsworth R (1991) Reflexes from the heart. Physiol Rev 71:617-658

55. Ray CA, Saito M (1999) The cardiopulmonary baroreflex. In: Saltin B, Boushel R, Secher NH, Mitchell JH (eds) Exercise and circulation in health and disease. Human Kinetics, Champaign, pp 43-51

56. Rea RF, Wallin BG (1989) Sympathetic nerve activity in arm and leg muscles during lower body negative pressure in humans. J Appl Physiol 66:2778-2781

57. Fu Q, Sugiyama Y, Kamiya A, Shamsuzzaman AS, Mano T (1998) Responses of muscle sympathetic nerve activity to lower body positive pressure. Am J Physiol 275:H1254-H1259

58. Fu Q, Sugiyama Y, Kamiya A, Mano T (2000) A comparison of autonomic responses in humans induced by two simulation models of weightlessness: lower body positive pressure and 6 degrees head-down tilt. J Auton Nerv Syst 80:101-107

59. Mack G, Nose H, Nadel ER (1988) Role of cardiopulmonary baroreflexes during dynamic exercise. J Appl Physiol 65:1827-1832

60. Raven PB, Chapleau MW (2014) Blood pressure regulation XI: overview and future research directions. Eur J Appl Physiol 114:579-586

61. Katayama K, Ishida K, Saito M, Koike T, Hirasawa A, Ogoh $\mathrm{S}$ (2014) Enhanced muscle pump during mild dynamic leg exercise inhibits sympathetic vasomotor outflow. Physiol Rep 2:e12070

62. Ogoh S, Fisher JP, Fadel PJ, Raven PB (2007) Increases in central blood volume modulate carotid baroreflex resetting during dynamic exercise in humans. J Physiol 581:405-418

63. Dempsey JA, Sheel AW, St Croix CM, Morgan BJ (2002) Respiratory influences on sympathetic vasomotor outflow in humans. Respir Physiol Neurobiol 130:3-20

64. Eckberg DL, Nerhed C, Wallin BG (1985) Respiratory modulation of muscle sympathetic and vagal cardiac outflow in man. J Physiol 365:181-196

65. Seals DR, Suwarno NO, Dempsey JA (1990) Influence of lung volume on sympathetic nerve discharge in normal humans. Circ Res 67:130-141

66. Macefield VG, Wallin BG (1995) Modulation of muscle sympathetic activity during spontaneous and artificial ventilation and apnoea in humans. J Auton Nerv Syst 53:137-147

67. St Croix CM, Satoh M, Morgan BJ, Skatrud JB, Dempsey JA (1999) Role of respiratory motor output in within-breath modulation of muscle sympathetic nerve activity in humans. Circ Res 85:457-469

68. Dempsey JA (2012) New perspectives concerning feedback influences on cardiorespiratory control during rhythmic exercise and on exercise performance. J Physiol 590:4129-4144

69. Stickland MK, Morgan BJ, Dempsey JA (2008) Carotid chemoreceptor modulation of sympathetic vasoconstrictor outflow during exercise in healthy humans. J Physiol 586:1743-1754
70. Johnson BD, Babcock MA, Suman OE, Dempsey JA (1993) Exercise-induced diaphragmatic fatigue in healthy humans. J Physiol 460:385-405

71. Romer LM, Polkey MI (2008) Exercise-induced respiratory muscle fatigue: implications for performance. J Appl Physiol 104:879-888

72. Harms CA, Wetter TJ, McClaran SR, Pegelow DF, Nickele GA, Nelson WB, Hanson NP, Dempsey JA (1998) Effects of respiratory muscle work on cardiac output and its distribution during maximal exercise. J Appl Physiol 85:609-618

73. St Croix CM, Morgan BJ, Wetter TJ, Dempsey JA (2000) Fatiguing inspiratory muscle work causes reflex sympathetic activation in humans. J Physiol 529:493-504

74. Katayama K, Itoh Y, Saito M, Koike T, Ishida K (2015) Sympathetic vasomotor outflow and blood pressure increase during exercise with expiratory resistance. Physiol Rep 3:e12421

75. Katayama K, Smith JR, Goto K, Shimizu K, Saito M, Ishida K, Koike T, Iwase S, Harms CA (2018) Elevated sympathetic vasomotor outflow in response to increased inspiratory muscle activity during exercise is less in young women compared with men. Exp Physiol 103:570-580

76. Dempsey JA, Amann M, Romer LM, Miller JD (2008) Respiratory system determinants of peripheral fatigue and endurance performance. Med Sci Sports Exerc 40:457-461

77. Hill JM (2000) Discharge of group IV phrenic afferent fibers increases during diaphragmatic fatigue. Brain Res 856:240-244

78. Sheel AW, Boushel RC, Dempsey JA (2018) Competition for blood flow distribution between respiratory and locomotor muscles: implications for muscle fatigue. J Appl Physiol 125:820-831

79. Dominelli PB, Katayama K, Vermeulen TD, Stuckless TJR, Brown CV, Foster GE, William Sheel A (2018) Work of breathing influences muscle sympathetic nerve activity during semirecumbent cycle exercise. Acta Physiol 225:e13212

80. Saito M, Mano T, Abe H, Iwase S (1986) Responses in muscle sympathetic nerve activity to sustained hand-grips of different tensions in humans. Eur J Appl Physiol Occup Physiol 55:493-498

81. Saito M (1995) Differences in muscle sympathetic nerve response to isometric exercise in different muscle groups. Eur J Appl Physiol Occup Physiol 70:26-35

82. Wallin BG (1984) Muscle sympathetic activity and plasma concentrations of noradrenaline. Acta Physiol Scand Suppl 527:21-24

83. Seals DR (1989) Influence of muscle mass on sympathetic neural activation during isometric exercise. J Appl Physiol 67:1801-1806

84. Kamiya A, Michikami D, Fu Q, Niimi Y, Iwase S (2000) Muscle sympathetic nerve activity (MSNA) during high-intensity, isometric leg exercise in humans. Environ Med 44:49-52

85. Ray CA, Mark AL (1993) Augmentation of muscle sympathetic nerve activity during fatiguing isometric leg exercise. J Appl Physiol 75:228-232

86. Ray CA, Rea RF, Clary MP, Mark AL (1992) Muscle sympathetic nerve responses to static leg exercise. J Appl Physiol 73:1523-1529

87. Saito M, Kagaya A, Ogita F, Shinohara M (1992) Changes in muscle sympathetic nerve activity and calf blood flow during combined leg and forearm exercise. Acta Physiol Scand 146:449-456

88. Pott F, Ray CA, Olesen HL, Ide K, Secher NH (1997) Middle cerebral artery blood velocity, arterial diameter and muscle sympathetic nerve activity during post-exercise muscle ischaemia. Acta Physiol Scand 160:43-47

89. Incognito AV, Doherty CJ, Nardone M, Lee JB, Notay K, Seed JD, Millar PJ (2019) Evidence for differential control of 
muscle sympathetic single units during mild sympathoexcitation in young healthy humans. Am J Physiol Heart Circ Physiol 316:H13-H23

90. Batman BA, Hardy JC, Leuenberger UA, Smith MB, Yang QX, Sinoway LI (1994) Sympathetic nerve activity during prolonged rhythmic forearm exercise. J Appl Physiol 76:1077-1081

91. Saito M, Mano T (1991) Exercise mode affects muscle sympathetic nerve responsiveness. Jpn J Physiol 41:143-151

92. Dominelli PB, Katayama K, Vermuelen TD, Stuckless TJ, Brown CV, Foster GE, Sheel AW (2018) Work of breathing influences muscle sympathetic nerve activity during whole-body execise. Med Sci Sports Exerc 50:122 (Abstract)

93. Katayama K, Yamashita S, Ishida K, Iwamoto E, Koike T, Saito M (2013) Hypoxic effects on sympathetic vasomotor outflow and blood pressure during exercise with inspiratory resistance. Am J Physiol Regul Integr Comp Physiol 304:R374-R382

94. Coyle EF, Gonzalez-Alonso J (2001) Cardiovascular drift during prolonged exercise: new perspectives. Exerc Sport Sci Rev 29:88-92

95. Rowell LB (1993) Control of regional blood flow during dynamic exercise. In: Rowell LB (ed) Human cardiovascular control. Oxford University Press, New York, pp 204-254

96. Ekelund LG (1967) Circulatory and respiratory adaptation during prolonged exercise. Acta Physiol Scand Suppl 292:1-38

97. Niimi Y, Matsukawa T, Sugiyama Y, Shamsuzzaman AS, Ito H, Sobue G, Mano T (1997) Effect of heat stress on muscle sympathetic nerve activity in humans. J Auton Nerv Syst 63:61-67

98. Cui J, Blaha C, Sinoway LI (2016) Whole body heat stress attenuates the pressure response to muscle metaboreceptor stimulation in humans. J Appl Physiol 121:1178-1186

99. Hines EA, Brown GE (1936) The cold pressor test for measuring the reactibility of the blood pressure: data concerning 571 normal and hypertensive subjects. Am Heart J 11:1-9

100. Fagius J, Karhuvaara S, Sundlof G (1989) The cold pressor test: effects on sympathetic nerve activity in human muscle and skin nerve fascicles. Acta Physiol Scand 137:325-334

101. Fagius J, Kay R (1991) Low ambient temperature increases baroreflex-governed sympathetic outflow to muscle vessels in humans. Acta Physiol Scand 142:201-209

102. Saito M, Mano T, Iwase S, Koga K, Abe H, Yamazaki Y (1988) Responses in muscle sympathetic activity to acute hypoxia in humans. J Appl Physiol 65:1548-1552

103. Rowell LB, Johnson DG, Chase PB, Comess KA, Seals DR (1989) Hypoxia raises muscle sympathetic activity but not norepinephrine in resting humans. J Appl Physiol 66:1736-1743
104. Somers VK, Mark AL, Zavala DC, Abboud FM (1989) Influence of ventilation and hypocapnia on sympathetic nerve responses to hypoxia in normal humans. J Appl Physiol 67:2095-2100

105. Smith ML, Muenter NK (2000) Effects of hypoxia on sympathetic neural control in humans. Respir Physiol 121:163-171

106. Seals DR, Johnson DG, Fregosi RF (1991) Hypoxia potentiates exercise-induced sympathetic neural activation in humans. J Appl Physiol 71:1032-1040

107. Saito M, Abe H, Iwase S, Koga K, Mano T (1991) Muscle sympathetic nerve responsiveness to static contraction is not altered under hypoxia. Jpn J Physiol 41:775-783

108. Bubb WJ, Howley ET, Cox RH (1983) Effects of various levels of hypoxia on plasma catecholamines at rest and during exercise. Aviat Space Environ Med 54:637-640

109. Clancy LJ, Critchley JA, Leitch AG, Kirby BJ, Ungar A, Flenley DC (1975) Arterial catecholamines in hypoxic exercise in man. Clin Sci Mol Med 49:503-506

110. Escourrou P, Johnson DG, Rowell LB (1984) Hypoxemia increases plasma catecholamine concentrations in exercising humans. J Appl Physiol 57:1507-1511

111. Rowell LB, Blackmon JR, Kenny MA, Escourrou P (1984) Splanchnic vasomotor and metabolic adjustments to hypoxia and exercise in humans. Am J Physiol 247:H251-H258

112. Wallin BG, Morlin C, Hjemdahl P (1987) Muscle sympathetic activity and venous plasma noradrenaline concentrations during static exercise in normotensive and hypertensive subjects. Acta Physiol Scand 129:489-497

113. Seals DR, Jones PP, Davy KP (2001) Autonomic nervous system. In: Hornbein TF, Schoene RB (eds) High altitude. Mercel Dekker, NewYork, pp 425-442

114. Folkow B, Di Bona GF, Hjemdahl P, Toren PH, Wallin BG (1983) Measurements of plasma norepinephrine concentrations in human primary hypertension. A word of caution on their applicability for assessing neurogenic contributions. Hypertension 5:399-403

115. Leuenberger U, Gleeson K, Wroblewsski K, Prophet S, Zelis R, Zwillich C, Sinoway L (1991) Norepinephrine clearance is increased during acute hypoxemia in humans. Am J Physiol 261:H1659-H1664

Publisher's Note Springer Nature remains neutral with regard to jurisdictional claims in published maps and institutional affiliations. 